\title{
The dobutamine stress test as an alternative to exercise testing after acute myocardial infarction
}

\author{
D MANNERING, * T CRIPPS, $\dagger$ G LEECH, $\dagger$ N MEHTA, * H VALANTINE, * \\ S GILMOUR, * E D BENNETT*
}

\begin{abstract}
From the Department of Medicine $1^{\star}$ and Cardiological Sciences, $†$ St George’s Hospital Medical School, London
\end{abstract}

SUMMARY Three weeks after myocardial infarction in 50 patients the effect of the infusion of a graded dose of dobutamine was compared with that of symptom limited treadmill exercise testing. The following variables were measured: blood pressure, heart rate, ST segment changes, Doppler aortic blood flow, and cross sectional echocardiographic dimensions. The heart rate and double product increased more during exercise than during dobutamine infusion, while maximum acceleration in the ascending aorta increased more during dobutamine infusion than during exercise. Significant ST depression was recorded in 22 patients during exercise and in 24 during dobutamine infusion; the concordance between the two tests was $88 \%$. In all cases in which ST segment depression occurred in both tests the site of ST depression was the same. Dobutamine stress testing is an alternative to exercise testing in patients after myocardial infarction.

Exercise stress testing has an established place in the assessment of patients after acute mycardial infarction. ${ }^{1}$ Many patients complete an exercise test without difficulty and gain encouragement from their performance. A sizeable minority, however, are not able to perform an adequate test because of anxiety, poor motivation, peripheral vascular disease, or musculoskeletal or neurological disorders. Furthermore, imaging techniques such as echocardiography cannot usually be performed satisfactorily during exercise.

Methods other than exercise have been developed to induce ischaemia in patients with ischaemic heart disease, including dipyridamole thallium imaging, ${ }^{23}$ atrial pacing, ${ }^{4}$ and inotropic stimulation with isoprenaline, dopamine, or dobutamine..$^{5-7}$ Few reports, however, examine the value of inotropic stimulation as a method of testing for residual ischaemia in patients after infarction.

We have studied the electrocardiographic and haemodynamic effects of graded doses of intravenous dobutamine in patients early after acute myocardial infarction and have compared these changes with

Requests for reprints to Dr T Cripps, Department of Cardiological Sciences, St George's Hospital Medical School, Cranmer Terrace, Tooting, London SW 17 ORE.

Accepted for publication 4 January 1988 those occurring during exercise testing in the same patients.

\section{Patients and methods}

\section{PATIENTS}

Exercise and dobutamine stress tests were performed three weeks after acute myocardial infarction in fifty patients (mean (SD) age 56 (5), range 35-69). Nine $(18 \%)$ of the patients were women. The diagnosis of acute myocardial infarction was based on at least two of three criteria: (a) a history of chest pain suggestive of myocardial ischaemia persisting for at least 30 minutes; $(b)$ evolution of new pathological $Q$ waves or persistent ST-T wave changes suggestive of non- $Q$ wave infarction; $(c)$ a rise in the concentrations of aspartate transaminase, hydroxybutyrate dehydrogenase, or creatine kinase to at least twice the upper limits of the reference ranges. The resting electrocardiogram showed anterior infarction in 16 patients, inferior in 22, lateral in four, true posterior in two, and non- $Q$ wave infarction in six. Three $(6 \%)$ patients had a history of a previous myocardial infarction. Patients with bundle branch block or nonischaemic valvar heart disease were excluded. Patients were randomly selected for the study before the exercise test and their written consent was obtained. 


\section{EXERCISE STRESS TESTING}

Three weeks after myocardial infarction patients performed symptom limited treadmill exercise testing according to the Bruce protocol. A 12 lead electrocardiogram was recorded before exercise, at the end of each stage, and at peak exercise. Leads II, V2, and V5 were monitored continuously. Blood pressure was measured in the right arm by sphygmomanometry at the same time as the electrocardiogram was recorded. The double product, heart rate $\times$ systolic blood pressure, was calculated at rest and at peak exercise. A positive test was defined by the development of $\geqslant 1 \mathrm{~mm}$ of horizontal or downsloping ST segment depression $80 \mathrm{~ms}$ after the J point in any lead except aVR.

Stroke volume and cardiac output were determined by transcutaneous continuous wave Doppler ultrasound and $M$ mode echocardiography as previously described. ${ }^{8}$ Blood flow in the ascending aorta was measured from the suprasternal notch by a bidirectional continuous wave Doppler blood velocity meter (Bach Simpson BVM 202 transmitting at $2 \cdot 2 \mathrm{MHz}$ or Quinton Exerdop transmitting at 3.0 $\mathrm{MHz}$ ) The systolic velocity integral and the maximum acceleration were obtained from the aortic blood velocity signals recorded at rest and at peak exercise. ${ }^{9}$ The cross sectional area of the aortic root was measured at rest by $\mathbf{M}$ mode echocardiography. The average systolic aortic root diameter was determined from the $\mathrm{M}$ mode recordings by planimetry. ${ }^{10}$

Exercise was continued until one of the following end points developed: $(a)>3 \mathrm{~mm}$ ST segment depression 80 ms after the J point; (b) a fall in the systolic blood pressure of $>10 \mathrm{mmHg}$; $(c)$ the development of chest pain, dyspnoea, fatigue, dizziness, or leg cramps.

\section{DOBUTAMINE STRESS TESTING}

Dobutamine stress testing was undertaken on the day after the exercise test. After a control period dobutamine was infused via an intravenous cannula placed in a vein in the left forearm. We increased the dose from $5 \mu \mathrm{g} / \mathrm{kg} / \mathrm{min}$ up to a maximum of $20 \mu \mathrm{g} / \mathrm{kg} /$ $\min$ in steps of $5 \mu \mathrm{g} / \mathrm{kg} / \mathrm{min}$. Six to eight minutes after the start of each dose we recorded a 12 lead electrocardiogram, blood pressure, and Doppler aortic blood flow measurements.

Cross sectional echocardiographic studies were performed during the control period and during the peak dobutamine infusion rate with a Xonics 5500D or Hewlett-Packard 77020A system with a $3.5 \mathrm{MHz}$ transducer. Whenever possible, multiple images were obtained in the parasternal long axis and short axis (mitral valve and papillary muscle levels) views and the apical two and four chamber views. Images were recorded on to video tape and were analysed by an expert independent observer who was unaware of the other test findings. For quantitative analysis the left ventricle was divided into 16 segments according to a modified version of the convention described by Gibson et al. ${ }^{11}$ Segmental wall motion was determined by the observer's impression of the inward movement of the endocardium and the degree of myocardial thickening during systole. Each wall segment was assigned a number corresponding to the wall motion analysis: $-1=$ hyperkinetic, $0=$ normal, 1 = hypokinetic, 2 = akinetic, and $3=$ dyskinetic. The sum of the segmental scores was divided by the number of segments seen and a wall motion score index was thus derived. For the study to be regarded as acceptable, the same segments had to be imaged both at rest and during stress.

Dobutamine infusion was continued until one of the following end points: (a) development of $\geqslant 3 \mathrm{~mm}$ ST segment depression, (b) development of chest pain or dyspnoea, (c) development of frequent or complex ventricular arrhythmias, (d) attainment of the peak dose $(20 \mu \mathrm{g} / \mathrm{kg} / \mathrm{min})$.

Patients stopped taking $\beta$ blocking agents for at least 48 hours before the exercise test. Patients taking calcium antagonists, nitrates, or diuretics continued their medication throughout the studies.

\section{CARDIAC CATHETERISATION}

Cardiac catheterisation was carried out by either the Judkins' or Sones' technique within four weeks of the stress tests in 26 patients in whom there was a clinical indication for catheterisation (post-infarction angina, ST depression on exercise, or poor blood pressure response to exercise). The angiograms were evaluated by an experienced observer who was unaware of the other test findings. Disease was regarded as significant if there was a stenosis of $\geqslant 50 \%$ in the left mainstem coronary artery or $\geqslant 70 \%$ in the other vessels. Disease in the branches of left anterior descending, circumflex, and right coronary arteries was classified as disease of the main vessel.

\section{STATISTICAL ANALYSIS}

Two tailed Student's $t$ tests, paired when appropriate, were used to test for statistically significant differences in the continuous variables that we measured. The $\chi^{2}$ test was used for discrete variables. The mean and standard errors of the mean are shown; a value of at least $p<0.05$ was regarded as significant.

\section{Results}

HAEMODYNAMIC RESPONSES

Technically acceptable Doppler studies of aortic 
blood velocity were obtained in 38 patients during exercise and dobutamine administration. The table shows the haemodynamic responses to exercise and dobutamine. Systolic blood pressure, heart rate, double product, maximum acceleration, and cardiac output at peak exercise and peak dobutamine infusion rates were significantly higher than control values. Peak exercise produced a significantly greater increase in heart rate than peak dobutamine $(68 \%$ vs $44 \%, p<0.001)$ Similarly, peak exercise produced a greater increase in double product than peak dobutamine $(107 \%$ vs $77 \%, \mathrm{p}<0.001)$. In contrast, the increase in maximum acceleration in the ascending aorta was significantly greater with dobutamine than with exercise $(118 \%$ vs $51 \%, \mathrm{p}<0.001)$.

\section{ST SEGMENT CHANGES}

Significant ST segment depression was recorded in 22 patients during exercise and in 24 during dobutamine infusion; the concordance between the two tests was $88 \%(\mathrm{p}<0.01)$ :

\begin{tabular}{lrrr} 
& & \multicolumn{2}{c}{ Dobutamine } \\
& & - ve & + ve \\
\hline \multirow{2}{*}{ Exercise } & - ve & 24 & 4 \\
& + ve & 2 & 20
\end{tabular}

In all cases in which ST segment depression occurred in both tests, the site of ST depression was the same. ST segment depression started in one patient at $5 \mu \mathrm{g} /$ $\mathrm{kg} / \mathrm{min}$, in 10 at $10 \mu \mathrm{g} / \mathrm{kg} / \mathrm{min}$, in 10 at $15 \mu \mathrm{g} / \mathrm{kg} / \mathrm{min}$, and in three at $20 \mu \mathrm{g} / \mathrm{kg} / \mathrm{min}$ of dobutamine. The heart rate at the onset of important ST segment depression was significantly lower for dobutamine (93 (4) $\mathrm{min})$ than for exercise $(117(6) \mathrm{min})(\mathrm{p}<0.01)$. No patient had downsloping ST depression on dobutamine, though two patients developed downsloping ST depression during the recovery phase after exercise. In 10 patients with an exercise time of less than three minutes, $7(70 \%)$ also failed to reach the maximum dobutamine dose because of chest pain or ST depression. Fifteen $(94 \%)$ of the 16 patients who developed significant ST depression before three minutes of exercise again failed to reach the maximum dobutamine dose because of ST depression.

\section{WALL MOTION ABNORMALITIES DURING DOBUTAMINE INFUSION}

Technically acceptable cross sectional echocardiograms were obtained during control tests and at peak dobutamine infusions in $\mathbf{4 1}$ patients. In 20 patients the wall motion score index was higher at peak dobutamine infusion than during the baseline test, indicating increased wall motion abnormality. There was a significant association between the change in wall motion score index (WMSI) and the presence of significant ST segment depression at peak exercise $(\mathrm{p}<0.01)$.

$\begin{array}{lcc} & \text { WMSI } & \text { WMSI same } \\ & \text { less } & \text { or more } \\ \text { No ST segment depression } & 17 & 4 \\ \text { ST segment depression } & 3 & 17\end{array}$

In patients with no $S T$ segment changes mean wall motion score index was lower at peak dobutamine infusion $(0.44(0.13))$ than at baseline $(0.71(0.08))$, $\mathrm{p}<0.01$. In patients with significant $\mathrm{ST}$ depression, there was an increase in mean wall motion score index, though this did not reach statistical significance $(0.80(0.12))$ at peak dobutamine vs 0.63 $(0 \cdot 12)$ baseline). Three of the four patients with no ST segment depression but an increase in wall motion score index had widespread electrocardiographic abnormalities at rest caused by multiple previous infarctions.

\section{CATHETERISATION DATA}

Catheterisation data were available in 25 patients. Thirteen had three vessel disease, six had two vessel disease, and six had single vessel disease. Three of the patients with triple vessel disease had no significant ST changes during the dobutamine test; the remaining ten all showed a positive electrocardiographic response to dobutamine. All three patients with triple vessel disease but without ST changes on

Table Haemodynamic data (mean (SE)) during exercise and dobutamine infusion in 38 patients three weeks after acute myocardial infarction

\begin{tabular}{|c|c|c|c|c|c|c|}
\hline \multirow[b]{2}{*}{ Data } & \multicolumn{2}{|l|}{ Exercise } & \multicolumn{2}{|l|}{ Dobutamine } & \multicolumn{2}{|c|}{$\begin{array}{l}\text { p value for comparison between } \\
\text { exercise and dobutamine tests }\end{array}$} \\
\hline & Rest & Peak & Control & Peak & Rest & Peak \\
\hline $\begin{array}{l}\text { Systolic BP }(\mathrm{mm} \mathrm{Hg}) \\
\text { Heart rate (beats } / \mathrm{min}) \\
\text { Double product }\left(\mathrm{mm} \mathrm{Hg} / \mathrm{min} \times 10^{-2}\right. \\
\text { Maximum acceleration }\left(\mathrm{ms}^{2}\right) \\
\text { Stroke volume }(\mathrm{ml}) \\
\text { Cardiac output }(\mathrm{l} / \mathrm{min})\end{array}$ & $\begin{array}{l}122(3 \cdot 3) \\
81(2 \cdot 5) \\
99 \cdot 6(3 \cdot 9) \\
15 \cdot 9(0 \cdot 7) \\
68(3 \cdot 7) \\
5 \cdot 0(0 \cdot 3)\end{array}$ & $\begin{array}{l}150(4 \cdot 6)^{\star} \\
136(3 \cdot 6)^{\star} \\
206 \cdot 4(8 \cdot 9)^{\star} \\
24 \cdot 1(4 \cdot 0)^{\star} \\
63(4 \cdot 6) \\
8 \cdot 5(0 \cdot 7)^{\star}\end{array}$ & $\begin{array}{l}127(2 \cdot 9) \\
78(2) \\
95 \cdot 5(3 \cdot 0) \\
17 \cdot 3(0 \cdot 7) \\
77 \cdot 0(4 \cdot 7) \\
6 \cdot 0(0 \cdot 4)\end{array}$ & $\begin{array}{l}153(5 \cdot 8)^{\star} \\
112(3 \cdot 6)^{\star} \\
169(6 \cdot 9)^{\star} \\
37 \cdot 7(3 \cdot 3)^{\star} \\
74 \cdot 4(3 \cdot 9) \\
7 \cdot 8(0 \cdot 5)^{\star}\end{array}$ & $\begin{array}{l}\text { NS } \\
\text { NS } \\
\text { NS } \\
\text { NS } \\
<0.05 \\
<0.01\end{array}$ & $\begin{array}{l}\text { NS } \\
<0.001 \\
<0.001 \\
<0.001 \\
<0.05 \\
\text { NS }\end{array}$ \\
\hline
\end{tabular}

${ }^{\star} \mathrm{p}<0.05$ for comparison between resting and peak values. 
dobutamine had widespread electrocardiographic abnormalities at rest, and in all three there was a striking increase in wall motion abnormality shown by echocardiography during dobutamine stress, with a mean increase in wall motion score of $50 \%$, compared with a $175 \%$ decrease in wall motion score in those patients without ST depression who did not have three vessel disease. The increase in blood pressure during dobutamine was significantly smaller in those with three vessel disease than in those known to have two or one vessel disease (10 (15) vs 26 (17) $\mathrm{mm} \mathrm{Hg}, \mathrm{p}<0.02$ ).

\section{ADVERSE REACTIONS AND COMPLICATIONS}

Neither exercise nor dobutamine infusion caused any serious complications or adverse reactions. Five patients experienced angina on exertion during exercise.

Dobutamine infusion was stopped before $20 \mu \mathrm{g} /$ $\mathrm{kg} / \mathrm{min}$ in 20 patients for the following reasons: a sensation of pounding in the head in four (at $15 \mu \mathrm{g} /$ $\mathrm{kg} / \mathrm{min}$ ); chest pain in one (at $5 \mu \mathrm{g} / \mathrm{kg} / \mathrm{min}$ ); nausea in one $(10 \mu \mathrm{g} / \mathrm{kg} / \mathrm{min})$; shortness of breath in two (at 10 and $15 \mu \mathrm{g} / \mathrm{kg} / \mathrm{min}$ ); maximum heart rate for age and sex in three (at $15 \mu \mathrm{g} / \mathrm{kg} / \mathrm{min}$ ); systolic blood pressure $>200 \mathrm{~mm} \mathrm{Hg}$ in one (at $15 \mu \mathrm{g} / \mathrm{kg} / \mathrm{min}$ ); $3 \mathrm{~mm} \mathrm{ST}$ segment depression in three (one at 10 and two at 15 $\mu \mathrm{g} / \mathrm{kg} / \mathrm{min}) ;$ frequent or complex ventricular extrasystoles in two (at $15 \mu \mathrm{g} / \mathrm{kg} / \mathrm{min}$ ); and $>3 \mathrm{~mm}$ ST segment depression and complex extrasystoles in three (at $10 \mu \mathrm{g} / \mathrm{kg} / \mathrm{min}$ ). The onset of important ventricular extrasystoles started during dobutamine administration in eight patients; one patient had nonsustained uniform ventricular tachycardia of ten beats, four patients developed occasional ventricular couplets, and three developed $>10$ ventricular extrasystoles/minute at the peak dose. In seven out of the 50 patients the frequency of extrasystoles increased on exercise, but none had ventricular tachycardia. In no patient in whom the results of exercise and dobutamine were discordant with respect to ST depression was either test stopped because of adverse effects other than ST depression or chest pain. In all cases, the effects of dobutamine, in terms of heart rate, blood pressure, ST depression, and adverse effects (where these occurred) subsided very quickly, within one minute in most cases, without further treatment once the infusion was stopped.

\section{Discussion}

ST depression on exercise ${ }^{1}$ and the haemodynamic response to exercise ${ }^{12-14}$ are valuable in the detection of multivessel disease and in predicting mortality in patients after acute myocardial infarction. The value of the exercise test is, however, limited in a substan- tial minority of patients by anxiety or pre-existing musculoskeletal, neurological, or pulmonary disease. The value of the test is also limited in those with widespread electrocardiographic abnormalities at rest, because in these patients the electrocardiographic changes may be modified, and imaging techniques are difficult to perform during exercise. While several alternative and often excellent techniques have been developed to allow stress testing and cardiac imaging without exercise in patients with ischaemic heart disease, including the dipyridamolethallium test, ${ }^{23}$ exercise radionuclide ventriculography, ${ }^{12-14}$ and atrial pacing-echocardiography, ${ }^{4}$ these tests are not widely used because of the specialised equipment and expertise that they require. Such tests cannot usually be performed in the district general hospital, to which most patients with acute myocardial infarction are admitted. The advantage of the test that we have described is that it requires only simple, familiar equipment. In nearly all of our patients, there was concordance between the occurrence of ST changes on dobutamine and during exercise, and so the tests may be regarded as providing similar information.

We also found that, although this was not an essential part of the test, in some patients echocardiography could be performed easily during dobutamine infusion and did provide extra information: in the three patients without significant ST changes during dobutamine in whom triple vessel disease was demonstrated, there was a striking increase in wall motion abnormality during dobutamine infusion. In these three patients any ST changes on exercise were obscured by widespread ST abnormalities at rest caused by previous infarction; dobutamine infusion with echocardiography may thus provide a non-invasive technique for identifying three vessel disease in such patients. It must be emphasised, however, that in many patients detailed echocardiographic analysis of wall motion is not feasible and also that assessment of wall motion is subjective. Considerable expertise is needed to detect small changes in wall motion and such changes are probably not reliable enough to be of much value in practice. In cases in which there are considerable changes, however, useful conclusions may be drawn. The dobutamine stress test may also prove to be of value when combined with other forms of cardiac imaging, such as radionuclide studies.

Although the use of inotrope infusion tests to induce myocardial ischaemia in patients with ischaemic heart disease has been reported before, ${ }^{57}$ experience in the early post-infarction period is limited. Berthe et al have recently shown that cross sectional echocardiography with dobutamine testing was better than pre-discharge submaximal bicycle 
exercise testing for the detection of three vessel disease after infarction. ${ }^{15}$ We found that the dobutamine test was also of value three weeks after acute infarction when symptom limited treadmill exercise was performed.

We were able to examine in more detail the mechanism of ischaemia during dobutamine infusion. The double product was lower during dobutamine administration since although the systolic blood pressure increased to a comparable extent, the increase in heart rate was less on exercise. Maximum acceleration, on the other hand, increased to a much greater extent during dobutamine infusion than during exercise. The ischaemia produced during dobutamine infusion therefore seems to be caused predominantly by an increase in the inotropic state rather than through an increase in heart rate (as it is during exercise). In this small study we have not been able to assess fully the ability of the dobutamine stress test to assist in distinguishing between patients with triple vessel disease and those with single and double vessel disease in the same way in which this is sometimes possible with exercise. ${ }^{16}$ None the less, as with exercise testing, those with triple vessel disease did have a smaller increase in blood pressure during the dobutamine test than those without three vessel disease. Furthermore, the only patient with very early onset ST depression on dobutamine had severe three vessel disease; but none of those in whom ST depression occurred late (at a dose of $20 \mu \mathrm{g} / \mathrm{kg} / \mathrm{min}$ ) had triple vessel disease. Seven out of the ten patients who were unable to complete more than three minutes of exercise also developed ischaemia before the maximum dobutamine dose, and fifteen of the sixteen patients who developed ST depression within the first three minutes of exercise developed ischaemia before the maximum dose of dobutamine was reached. No downsloping ST depression was seen with dobutamine, though this could have been partly because the effects of dobutamine were more short lived than the effects of exercise, so that the same degree of ischaemia did not develop. Although a larger study would be needed to establish the discriminatory power of the dobutamine test for identification of three vessel disease, these preliminary results suggest that the dobutamine test would be at least as good as exercise.

In conclusion, we found that the use of graded doses of dobutamine infusion in patients three weeks after myocardial infarction produced changes in ST segment and blood pressure that resembled those that occurred on treadmill exercise. It seems that ischaemia is induced by increased inotropism during this test, despite the smaller increase in heart rate than on exercise. The test is economical and requires only familiar, widely available equipment. Some arrhythmias are induced, however, so that the test may not be suitable in patients with a tendency to arrhythmia; full resuscitation facilities should be available when the test is performed. Dobutamine stress testing is a possible alternative to exercise testing in patients after myocardial infarction.

DM was supported during this study by Eli Lilly and Company, England.

\section{References}

1 Theroux P, Waters DD, Halphen C, Debaiseux J-C, Mizgala HF. Prognostic value of exercise testing soon after myocardial infarction. $N$ Engl $J$ Med 1979;301:341-5.

2 Josephson MA, Brown BG, Hecht HS, et al. Noninvasive detection and localization of coronary stenosis in patients: comparison of resting dipyridamole and exercise thallium-201 myocardial perfusion imaging. Am Heart J 1982;103:1008-18.

3 Walker PR, James MA, Wilde RPH, Wood CH, Rees JR. Dipyridamole combined with exercise for thallium-201 myocardial imaging. $\mathrm{Br}$ Heart $J$ 1986;55:321-9.

4 Iliceto S, D'Ambrosio G, Sorino M, et al. Comparison of post exercise and transesophageal atrial pacing two-dimensional echo-cardiography for detection of coronary artery disease. Am J Cardiol 1986;57: 547-53.

5 Manca C, Bianchi G, Effendy FN, Bolognesi R, Cucchini F, Visioli O. Comparison of five different stress testing methods in the ECG diagnosis of coronary artery disease. Cardiology 1979;64:325-32.

6 Wisenberg G, Zawadowski AG, Gerbhardt VA, et al. Dopamine: its potential for inducing ischaemic left ventricular dysfunction. J Am Coll Cardiol 1985;6:84-92.

7 Mason JR, Palac RT, Freeman ML, et al. Thallium scintigraphy during dobutamine infusion: nonexercise dependent screening test for coronary disease. Am Heart J 1984;107:481-5.

8 Mehta N, Iyawe VI, Cummin ARC, Bayley S, Saunders KB, Bennett ED. Validation of a Doppler technique for beat to beat measurement of cardiac output. Clin Sci 1985;69:377-82.

9 Mehta N, Bennett ED. Impaired left ventricular function in acute myocardial infarction assessed by Doppler measurement of ascending aortic blood velocity and maximum acceleration. Am J Cardiol 1986;57:1052-8.

10 Greenfield A, Patel S. Relationship between aortic pressure and diameter in the ascending aorta in man. Circ Res 1962;10:778-83.

11 Gibson RS, Bishop HL, Stamm RB, Crampton RS, Beller GA, Martin RP. Value of early two dimensional echocardiography in patients with acute myocardial infarction. Am J Cardiol 1982;49:1110-9.

12 Nicod P, Corbett JR, Firth BG, et al. Prognostic value 
of resting and submaximal exercise radionuclide ventriculography after acute myocardial infarction in high-risk patients with single and multivessel disease. Am J Cardiol 1983;52:30-6.

13 Fubini A, Cecchi E, Spinnler MT, et al. Use of radionuclide angiography and an electrocardiographic stress test to diagnose multivessel disease after a first episode of uncomplicated myocardial infarction. Br Heart J 1986;55:535-42.

14 Corbett JR, Dehmer GJ, Lewis SE, et al. The prognostic value of submaximal exercise testing with radionuclide ventriculography before hospital discharge in patients with recent myocardial infarction. Circulation 1981;64:535-44.

15 Berthe C, Pierard LA, Hiernaux M, et al. Predicting the extent and location of coronary artery disease in acute myocardial infarction by echocardiography during dobutamine infusion. Am J Cardiol 1986;58:1167-72.

16 Mannering D, Bennett ED, Ward DE, et al. Accurate detection of triple vessel disease in patients with exercise induced ST segment depression after infarction. Br Heart J 1987;57:133-8. 